\title{
Suboptimal Clinical Documentation in Young Children with Severe Obesity at Tertiary Care Centers
}

\author{
Cassandra C. Brady, ${ }^{1}$ Vidhu V. Thaker, ${ }^{2,3}$ Todd Lingren, ${ }^{4}$ Jessica G. Woo, ${ }^{4}$ \\ Stephanie S. Kennebeck, ${ }^{4}$ Bahram Namjou-Khales, ${ }^{4}$ Ashton Roach, ${ }^{4}$ Jonathan P. Bickel, ${ }^{2,3}$ \\ Nandan Patibandla, ${ }^{2}$ Guergana K. Savova, ${ }^{2,3}$ Imre Solti, ${ }^{4}$ Ingrid A. Holm, ${ }^{2,3}$ John B. Harley, \\ Isaac S. Kohane, ${ }^{2,3}$ and Nancy A. Crimmins ${ }^{4}$ \\ ${ }^{1}$ Vanderbilt University School of Medicine, Nashville, TN, USA \\ ${ }^{2}$ Boston Children's Hospital, Boston, MA, USA \\ ${ }^{3}$ Harvard Medical School, Boston, MA, USA \\ ${ }^{4}$ Cincinnati Children's Hospital Medical Center, Cincinnati, OH, USA
}

Correspondence should be addressed to Vidhu V. Thaker; vidhu.thaker@childrens.harvard.edu

Received 16 May 2016; Revised 4 August 2016; Accepted 8 August 2016

Academic Editor: Naveed Hussain

Copyright (C) 2016 Cassandra C. Brady et al. This is an open access article distributed under the Creative Commons Attribution License, which permits unrestricted use, distribution, and reproduction in any medium, provided the original work is properly cited.

\begin{abstract}
Background and Objectives. The prevalence of severe obesity in children has doubled in the past decade. The objective of this study is to identify the clinical documentation of obesity in young children with a BMI $\geq 99$ th percentile at two large tertiary care pediatric hospitals. Methods. We used a standardized algorithm utilizing data from electronic health records to identify children with severe early onset obesity (BMI $\geq 99$ th percentile at age $<6$ years). We extracted descriptive terms and ICD-9 codes to evaluate documentation of obesity at Boston Children's Hospital and Cincinnati Children's Hospital and Medical Center between 2007 and 2014. Results. A total of 9887 visit records of 2588 children with severe early onset obesity were identified. Based on predefined criteria for documentation of obesity, $21.5 \%$ of children (13.5\% of visits) had positive documentation, which varied by institution. Documentation in children first seen under 2 years of age was lower than in older children (15\% versus 26\%). Documentation was significantly higher in girls (29\% versus $17 \%, p<0.001$ ), African American children (27\% versus 19\% in whites, $p<0.001$ ), and the obesity focused specialty clinics ( $70 \%$ versus $15 \%$ in primary care and $9 \%$ in other subspecialty clinics, $p<0.001)$. Conclusions. There is significant opportunity for improvement in documentation of obesity in young children, even years after the 2007 AAP guidelines for management of obesity.
\end{abstract}

\section{Background}

The epidemic of obesity continues unabated. According to the National Health and Nutrition Examination Survey (NHANES) 2011-2012, 8.4\% of children aged 2-5 years are obese $[1,2]$. Despite reports of recent stabilization of overall obesity prevalence, rates of severe obesity ( $\geq$ Class 2 obesity, defined as BMI $>120 \%$ of 95 th percentile) have increased by over $50 \%$ since 2000 [3-5], especially in the youngest children [6]. Childhood obesity tends to track into adulthood and portends a dramatic increases in diseases such as atherogenic heart disease, type 2 diabetes mellitus (T2DM), dyslipidemia, sleep apnea, and early mortality [4,7-9]. Response to medical intervention of obesity is more effective in early childhood compared to adolescents and adults $[10,11]$. Hence, prevention and intervention for management of obesity in early childhood are optimal.

In 2007, the American Academy of Pediatrics (AAP) published expert committee recommendations on the prevention, assessment, and treatment of overweight and obese children. The committee emphasized assessment of body mass index (BMI) at every well-child visit as a method of identifying obesity and the first important step in the creation of a chronic care model with community involvement [12]. However, several years after the guidelines, the rates of identification of overweight and obese status in children continue 
to be low. Prior studies have shown poor documentation of obesity in pediatric patients using ICD-9 codes [13-16]. Few studies have investigated the documentation of the obesity by providers in the progress notes.

Widespread availability of electronic health records (EHRs) and tools such as automatic BMI calculation [17] and alerts for high BMI [18-20] have improved the documentation of obesity in some settings. However, there is limited data on documentation in children under 6 years of age with severe early onset obesity, where the possibility of long-term adverse effects is the highest and early intervention is critical.

This study seeks to identify the rates of clinical documentation of obesity in children under 6 years of age, using the EHRs at two large pediatric academic medical centers. We used structured data such as ICD-9 codes and nonstructured data such as provider notes using natural language processing (NLP) to assess documentation. Based on prior studies, we hypothesized that rates of documentation of obesity in the youngest age group, even among those with severe obesity, would be low.

\section{Methods}

2.1. Study Design. This is a retrospective cohort study utilizing EHR data for children with severe obesity between the ages of 1-5.99 years, from both outpatient and inpatient settings at Cincinnati Children's Hospital Medical Center (CCHMC) and Boston Children's Hospital (BCH) from 2007 to 2014. This study was conducted under the auspices of Electronic Medical Records and Genomics (eMERGE) network, a national consortium organized by the National Human Genome Research Institute (NHGRI). Institutional Review Board for research in human subjects approved the protocol at $\mathrm{CCHMC}$ and $\mathrm{BCH}$, under a waiver of informed consent.

2.2. Data Source. CCHMC has used EpicCare (Epic Systems Corporation, Madison, WI) since 2010 and BCH has used Cerner Solutions (Cerner Corporation, Kansas City, MO) since 2006. Data extraction was performed on the electronic patient records completed during routine clinical care at CCHMC from January 2010 through June 2012 and from January 2007 through November 2014 at BCH. Both inpatient and outpatient records were included.

2.3. Algorithm. As part of the eMERGE project, a validated electronic algorithm was established to identify cases of severe obesity using structured and nonstructured data fields captured in the EHR during clinical care [21]. BMI was calculated by the EHR systems from height (or length, if under the age of 2) and weight data recorded at the same visit by medical assistants and/or nurses during the course of routine clinical care. Age- and gender-specific reference BMI percentiles were automatically calculated within the EHR using Centers for Disease Control and Prevention (CDC) 2000 growth charts for children older than 24 months of age and World Health Organization (WHO) 2006 growth charts for children 12-23 months old. New evidence suggests that BMI is a more useful parameter to measure adiposity in children under 2 years of age, compared to weight-forlength [22]. To minimize biologically implausible values, any height- or length-for-age measurement $<-5 \mathrm{SD}$ were removed. Any absolute BMI $>60 \mathrm{~kg} / \mathrm{m}^{2}$ was also eliminated as biologically implausible for children $<6$ years of age. A positive case for severe obesity was defined as having a BMI $\geq 99$ th percentile [12] on two or more different encounters, with more than half of all measurements for that individual with $\mathrm{BMI}>75$ th percentile. If more than one recording was present for a given day, only the first recording for the day was included (Figure 1). Furthermore, if measurements were carried forward across several days of the same inpatient encounter, only the first day of that encounter was included in analysis. Of note, the definition of BMI $\geq 99$ th percentile for severe obesity was used, as this is readily available at the point of care for the physician. The current EHR systems are not adapted to calculate or display $120 \%$ of 95 th percentile in keeping with the current definition of severe obesity [23].

Known causes of obesity including endocrine (e.g., Cushing's syndrome), genetic (e.g., Prader-Willi syndrome), malignancy, and connective tissue disorders and diseases causing edema (e.g., renal failure) were excluded using ICD9 codes and written documentation (Table 1). We excluded these patients because we felt that providers might not document obesity in these patients, not because it was not recognized, but because there were more pressing medical issues to address or because the cause of the obesity was not felt to be endogenous. Prescription data was used to exclude patients on prolonged courses of steroids (longer than 14 consecutive days or three or more separate courses totaling more than 28 days in the six months prior to qualifying weight) or atypical antipsychotics. To validate the algorithm, a manual chart review of 200 charts was performed at each center by at least two physicians (pediatric endocrinology and emergency medicine). A systematic data collection of the chart review was maintained and an interrater reliability $>$ $85 \% F$ measure [24] and a positive predictive value of $>90 \%$ was achieved after the training phase. Any disagreements were adjudicated by discussion.

2.4. Documentation of Obesity. Following identification of cases of severe obesity by the algorithm, the available clinical notes and diagnosis codes were extracted for all cases. Natural language processing (NLP) was performed on the clinical notes using a regular expression search with descriptive obesity terms and phrases (Table 2). A broad selection of weight- and obesity-related terms was used to maximize sensitivity. Any encounter that had at least one term from the list in the notes or any of the listed diagnosis codes was considered to have documentation of obesity. Additionally, a notation of an ICD-9 code relevant to obesity in the problem list (Table 2) was considered as positive documentation. An automatic notation of BMI value in the growth chart was not considered documentation, as the EHRs were not configured to provide an alert for a certain percentile of BMI. Individuals were classified as having been "ever documented" if at least one severe obesity encounter showed documentation during the course of care. 


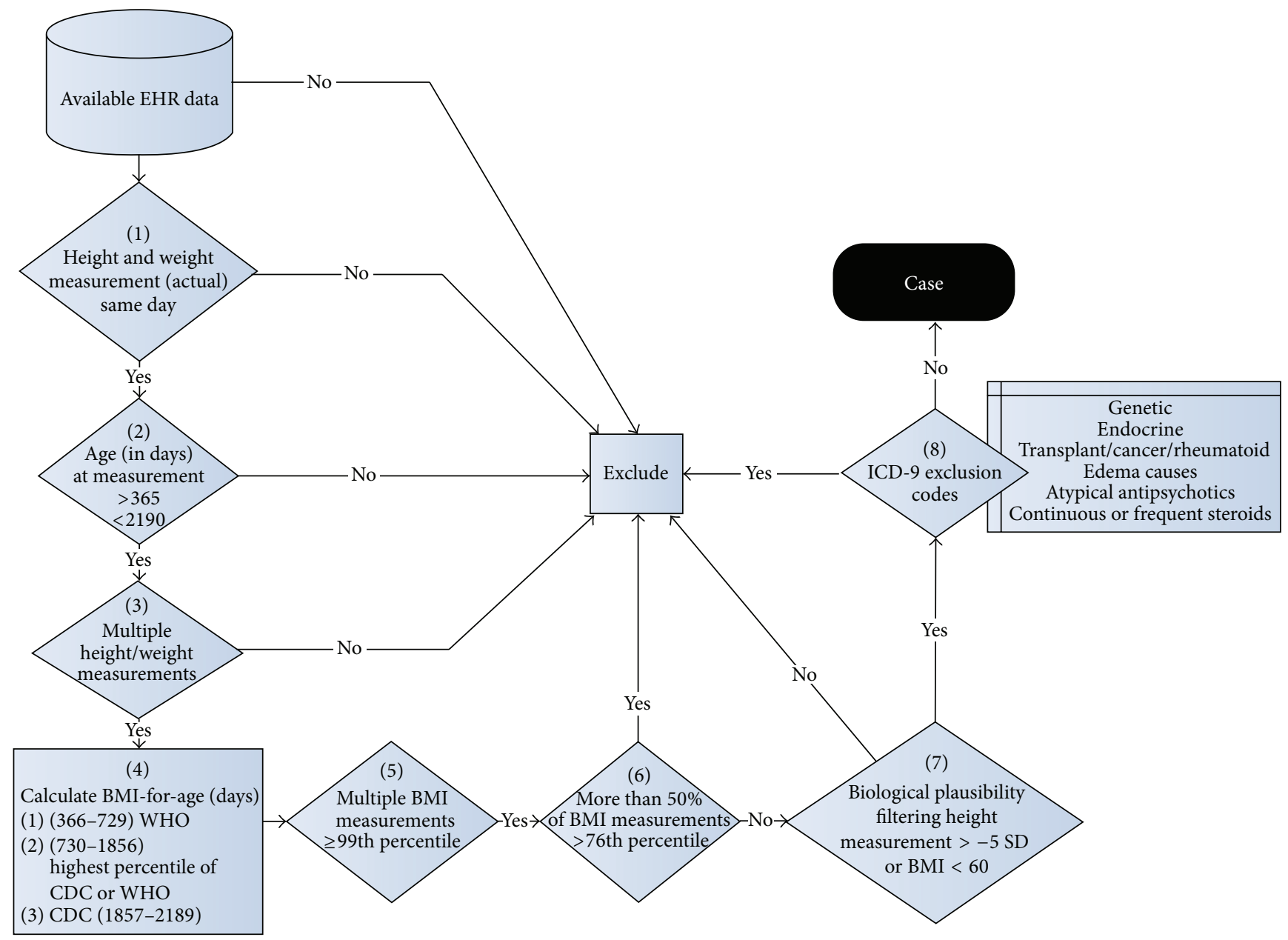

FIGURE 1: Severe early childhood obesity electronic algorithm. EHR data: available electronic medical record data. Patients required both a height and weight recorded on the same day with height or length $>-5$ SD for age and gender, at least 2 BMIs $\geq 99$ th percentile, and $>50 \%$ of all BMIs > 76th percentile.

2.5. Statistical Analysis. Analyses were conducted using SAS version 9.3 (SAS Institute, Cary, NC). Comparisons between centers, or within each center by obesity documentation status, were conducted using Wilcoxon Rank Sum analysis or Fisher's Exact test for continuous or categorical variables, respectively. $p$ values $<0.05$ were considered significant.

\section{Results}

3.1. Demographics. We identified a total of 30,463 records for review from $\mathrm{CCHMC}$ and $\mathrm{BCH}$ of children between the ages of 1-5.99 years that met the inclusion criteria for severe obesity without a pathological etiology. Of these, 891 records were eliminated for biologically implausible values of BMI > $60 \mathrm{~kg} / \mathrm{m}^{2}$ or height-for-age $<-5$ SD. Further, 2797 records were eliminated for BMI $<99$ th percentile. This is in keeping with the $90 \%$ PPV of the algorithm. All duplicate records for the same patient at the same encounter were removed, leaving a total of 9887 records of 2588 unique patients. These included 489 unique patients at CCHMC (encounters $=2399)$ and 2099 at $\mathrm{BCH}$ (encounters $=7488$ ).

The median age of patients at their first visit with a BMI $\geq 99$ th percentile was 34 months (IQR 17, 49), which differed between BCH and CCHMC (BCH 32 months (IQR 17, 48); CCHMC 41 months (IQR 21, 55); $p<0.001$ ). Overall, $64 \%$ of patients were male (BCH 65\%; CCHMC 61\%) and were not different by location $(p=0.12)$. Self-reported race and ethnicity varied by the institution, with more multiethnic representation at $\mathrm{BCH}$. Detailed demographic distribution of the cohort is provided in Table 3 .

3.2. Chart Documentation of Obesity. Using the a priori criteria for documentation of obesity, $21.5 \%$ of the unique patients (557/2588) had positive documentation of obesity. This rate varied by institution, with $40 \%$ ever documented at $\mathrm{CCHMC}$ and $17 \%$ at $\mathrm{BCH}(p<0.001)$. Ever documentation of obesity was lower in those children first seen at $<2$ years of age $(15 \%)$ compared to those first seen $>2$ years of age $(26 \%$, Table 4). Consistent with this, those ever being documented had a later age at first $\mathrm{BMI} \geq 99$ th percentile encounter than those never correctly documented, at both centers (both $p<0.001$ ), and had more encounters (median 4, IQR 3, 6) compared to those who were not (median 3, IQR 2, 4) (Table 4). The documentation was significantly higher in girls $(268 / 921=29 \%$ documented $)$ than in boys $(289 / 1667=$ $17 \%$ documented, $p<0.001)$. African American children 
TABLE 1: Diagnoses excluded from electronic health records (EHR) search.

\begin{tabular}{|c|c|c|}
\hline Category of exclusion & Conditions & ICD-9 codes \\
\hline \multirow{9}{*}{ Endocrine causes } & Type 2 diabetes mellitus & $250.00,250.02$ \\
\hline & Hypothyroidism & 244.9 \\
\hline & Growth hormone deficiency & 253.3 \\
\hline & Hypopituitarism & 253.2 \\
\hline & Adrenal insufficiency & 255.41 \\
\hline & Hypothalamic obesity & 259.8 \\
\hline & Precocious puberty & 259.1 \\
\hline & Cushing's syndrome & 255.0 \\
\hline & Type 1 diabetes mellitus & $250.01,250.03$ \\
\hline \multirow{5}{*}{ Genetic causes } & Down syndrome & 758.0 \\
\hline & Turner syndrome & 758.6 \\
\hline & Prader-Willi syndrome & 759.81 \\
\hline & Albright hereditary osteodystrophy & 756.59 \\
\hline & Bardet-Biedl/ Alström /Noonan/Carpenter's syndromes & 759.89 \\
\hline \multirow{6}{*}{ Steroid treatment } & Transplant & V42.x \\
\hline & Rejection & $996.8 \mathrm{x}$ \\
\hline & Juvenile rheumatoid arthritis & $714.3 \mathrm{x}$ \\
\hline & Inflammatory bowel disease & 555.9 \\
\hline & Cancer, brain tumor & 191.1, 191.1x, 201.x-208.x \\
\hline & Histiocytosis & 277.89 \\
\hline \multirow{6}{*}{ Edema-causing, gastrointestinal } & Congestive heart failure & 428.0 \\
\hline & Edema & 782.3 \\
\hline & Nephrotic syndrome & 581.9 \\
\hline & End-stage renal disease & 585.6 \\
\hline & Eosinophilic esophagitis & 530.13 \\
\hline & Ulcerative colitis, unspecified & 556.9 \\
\hline Psychiatric & Antipsychotic use & - \\
\hline
\end{tabular}

were more likely to have a documentation of obesity (115/419 $=27 \%$ documented) compared to white children $(237 / 1262$ $=19 \%$ documented, $p<0.001)$, which was consistent at both institutions (Table 4). Documentation of individual encounters was lower (13.5\% overall) than for each individual patient (21.5\%, Table 3$)$.

Most of the children with documentation of obesity were Class 2 obesity or higher [25]. At the time of first documentation of obesity (median 48 months, Table 5), the median BMI was $125 \%$ of 95 th percentile (IQR 116, 140) overall, somewhat lower for BCH (121\% of 95th percentile (IQR 114, 133)) than at CCHMC (133\% of 95th percentile (IQR $121,147), p<0.001)$. Documentation at the first encounter occurred $44 \%$ of the time overall and was more common for children $\geq 2$ years old ( $51 \%$ ) than children $<2$ years old (23\%, Table 5). There was a median lag overall of 1.5 months (IQR 0,13) after first encounter to documentation, which was somewhat longer at $\mathrm{BCH}(5$ months (IQR 0,18$))$ compared to CCHMC (0 months (IQR 0, 4), Table 5). Approximately half of all visits were documented for each child. The location of the encounter was also a significant factor in determining the documentation of obesity (Table 5). Children seen in the endocrine, nutrition, and obesity clinics had higher rates of documentation $70 \%$ of visits overall, compared to primary care (15\% of visits) or other subspecialties ( $9 \%$ of visits).

\section{Discussion}

The data from this study identifies poor rates of clinical documentation of severe obesity in young children at two large pediatric academic hospitals utilizing a new, validated EHR algorithm that uses structured and unstructured data (through NLP) to identify chart documentation of obesity. Rates of ever being recognized as obese in young children was $21.5 \%$ overall, varying by institution, and much less $(13.5 \%)$ if evaluated at an encounter level. Most children who were recognized to have some weight issue (based on a broad selection of weight-related terms) were not recognized in the clinical documentation as obesity or severe obesity, although they would qualify as severe obesity using BMI definition.

Poor documentation of obesity has been shown in previous studies: assessing ICD-9 codes for obesity based on discharge diagnoses identified only $1.7 \%$ of children with obesity (mean age for those with obesity not documented, $11.4 \pm 4.9$ years) [15]. Chart documentation in a general pediatrics clinic showed rates of $34.1 \%$ for overweight or obese children of all ages [26], similar to the documentation rates in our study. A national study reviewing documentation and ICD-9 codes in children 2-18 years old showed an $18 \%$ rate of identification of obesity [16]. Although these studies investigated identification in all age groups, there 
TABLE 2: Key terms and ICD-9 codes used to identify appropriate documentation within EHR.

(a)

\begin{tabular}{lc}
\hline \multicolumn{2}{c}{ Key words/terminology } \\
Obesity & Obese \\
\hline Severe obesity & Severely obese \\
Morbid obesity & Morbidly obese \\
Central obesity & Overweight \\
Abnormal weight gain & Excess adiposity \\
BMI $\geq 85$ th percentile & High weight \\
BMI $\geq 95$ th percentile & Unhealthy weight \\
BMI $\geq 99$ th percentile & Excess weight \\
Elevated body mass index & Elevated weight \\
Weight too great for length & Chunky \\
High weight for length & Heavy \\
& Heavy for age \\
\hline
\end{tabular}

(b)

ICD-9 coded conditions

\begin{tabular}{lc} 
Condition & ICD-9 codes \\
\hline Obesity, unspecified & 278.00 \\
Overweight and obesity & 278.0 \\
Morbid obesity & 278.01 \\
Overweight & 278.02 \\
Localized adiposity & 278.1 \\
Overweight, obesity, and other hyperalimentation & 278 \\
Abnormal weight gain & 783.1 \\
Other unspecified endocrine disorders & 259.8 \\
\hline
\end{tabular}

was little focus on the youngest age except for mention of poorer rates of documentation. We specifically studied the youngest children with severe obesity to leave out marginal cases and ensure that the degree of obesity was obvious to be acknowledged by the providers. At both institutions, the children who were identified appropriately had a significantly higher BMI than those not documented suggesting that the severity of the obesity played a role in the clinical documentation.

Our study is novel in that it focused on the youngest children. As eating patterns are established early in life, this is a key age to recognize and address obesity. Children who are overweight by kindergarten were found to have four times higher risk of progressing to an obese adolescence [9]. As severe obesity continues into late childhood and adolescence, they develop an increased risk for dyslipidemia, hypertension, and hyperinsulinemia compared to those who are not obese and those with lesser degree of adiposity (BMI between 95 and 99th percentile) $[4,7,8]$. Increasing BMI in children has also been associated with increased risk for other comorbidities [4] and premature death as a young adult [13]. In order to prevent these major complications, obese children must first be identified by medical providers at the youngest age possible for best outcomes.

Similar to previous studies, we identify poor rates of documentation despite evaluating both ICD-9 codes and progress notes. However, we show that the age at first identification of severe obesity was over 36 months at both institutions indicating that children $<36$ months old were more likely to be missed. Possible explanations for this could be the current lack of clinical guidance for using standardized BMI curves for children less than 24 months or difficulty in approaching this topic at an age where the definitive trajectory of BMI may not yet have been established. It is to be noted that the documentation in children $<2$ years old was much higher at CCHMC ( $49 \%$ versus $14 \%$ at $\mathrm{BCH})$. This perhaps reflects the practice differences due to the presence of a weight management clinic focused on children $<6$ years old at CCHMC. A lack of clinical focus on endocrine or nutrition issues may account for the gap between these specialty encounters at both sites (BCH: 69\%, CCHMC: 72\%) and other subspecialty clinics (9\% overall). However, even in clinics that should be addressing weight, such as nutrition and endocrine clinics, obesity was not documented at every encounter. The reasons for this are not clear: it could be that weight status was addressed and not documented. Yet, it could be that even these types of providers can be distracted from weight status when addressing non-weight-related chief complaints.

We show that males are less likely to be recognized at both institutions, despite a predominance of males in our study populations. Societal norms perhaps play a role and the younger males are viewed as "stocky" as opposed to obese, which may explain their lack of documentation. Interestingly at both institutions, Caucasians were not documented as often as African Americans. Whether this was due to provider bias is not known but may be potentially explained by the heightened awareness of obesity and its complications in the minority populations $[1,2]$.

Primary and tertiary medical providers must play an active role in obesity identification at all levels of care in these young children. For children without chronic illnesses, the most frequent encounters with medical professionals occur during the first two years of age. After two years of age, children have less frequent well-child visits. Primary care providers need to pay attention to obesity development in young children even for sick visits, as these visits may represent their only encounters with some families. Although primary care providers are the anchor for obesity management, tertiary care providers and subspecialists can play a valuable role in the identification of obesity, especially those likely to care for adiposity related complications. Common childhood illnesses such as asthma, injuries, and joint pain and abdominal issues can be attributed to obesity even at young ages. Furthermore, obesity in the critically ill patients can lead to acute respiratory distress syndrome, acute kidney injury, and other management difficulties [27-29]. Similarly, there is a higher rate of peri- and postoperative complications in obese individuals [29-31].

The strengths of this study are the use of data from two large tertiary care children's hospitals resulting in a large sample of young children. We were able to utilize NLP with a wide range of terms in addition to ICD-9 codes to assess documentation of obesity with a high sensitivity. Limitations include assessment of the providers thoughts and 
TABLE 3: Description of study populations.

\begin{tabular}{|c|c|c|c|c|}
\hline & Overall & $\mathrm{BCH}$ & CCHMC & $p$ value $^{*}$ \\
\hline \multicolumn{5}{|c|}{ (A) Patient-level summary } \\
\hline$N$ unique patients & 2588 & 2099 & 489 & \\
\hline Age at first $99 \%$ percentile visit (months), median [IQR] & $34[17,49]$ & $32[17,48]$ & $41[21,55]$ & $<0.001$ \\
\hline First $99 \%$ percentile visit $<2$ years $(\%)$ & $1032(40 \%)$ & $892(43 \%)$ & $140(29 \%)$ & $<0.001$ \\
\hline Sex (\% male) & $1667(64 \%)$ & $1367(65 \%)$ & $300(61 \%)$ & 0.12 \\
\hline \multicolumn{5}{|l|}{ Race (\%) } \\
\hline White & $1262(55 \%)$ & $935(51 \%)$ & $327(67 \%)$ & \multirow{4}{*}{$<0.001$} \\
\hline Black & $419(18 \%)$ & $337(18 \%)$ & $82(17 \%)$ & \\
\hline Other & $630(27 \%)$ & $552(30 \%)$ & $78(16 \%)$ & \\
\hline Unknown & 277 & 275 & 2 & \\
\hline \multicolumn{5}{|l|}{ Ethnicity $(\%)^{*}$} \\
\hline Hispanic/Latino & $369(20 \%)$ & $331(25 \%)$ & $38(8 \%)$ & \multirow{2}{*}{$<0.001$} \\
\hline Not Hispanic/Latino & $1437(80 \%)$ & $988(75 \%)$ & $449(92 \%)$ & \\
\hline Unknown & 786 & 780 & 6 & \\
\hline Patients ever correctly documented (\%) & $557(21.5 \%)$ & $362(17 \%)$ & $195(40 \%)$ & $<0.001$ \\
\hline \multicolumn{5}{|c|}{ (B) Visit-level summary } \\
\hline$N$ visits & 9887 & 7488 & 2399 & \multirow{3}{*}{$\begin{array}{c}0.05 \\
<0.001\end{array}$} \\
\hline Age at visit (months), median [IQR] & $43[23,56]$ & $42[23,56]$ & $45[23,58]$ & \\
\hline Sex (\% male) & $6432(65 \%)$ & $4957(66 \%)$ & $1475(61 \%)$ & \\
\hline \multicolumn{5}{|l|}{ Race $(\%)^{*}$} \\
\hline White & $5004(55 \%)$ & $3329(50 \%)$ & $1675(70 \%)$ & \multirow{4}{*}{$<0.001$} \\
\hline Black & $1523(17 \%)$ & $1180(18 \%)$ & $343(14 \%)$ & \\
\hline Other & $2513(28 \%)$ & $2143(32 \%)$ & $370(15 \%)$ & \\
\hline Unknown & 847 & 836 & 11 & \\
\hline \multicolumn{5}{|l|}{ Ethnicity $(\%)^{*}$} \\
\hline Hispanic/Latino & $1437(20 \%)$ & $1208(26 \%)$ & $229(10 \%)$ & \multirow{2}{*}{$<0.001$} \\
\hline Not Hispanic/Latino & $5597(80 \%)$ & $3435(74 \%)$ & $2162(90 \%)$ & \\
\hline Unknown & 2853 & 2845 & 8 & \\
\hline Visits correctly documented (\%) & $1336(13.5 \%)$ & $867(12 \%)$ & $467(19 \%)$ & $<0.001$ \\
\hline
\end{tabular}

${ }^{*} p$ value for differences between institutions; individuals with unknown race or ethnicity were not included in $p$ value calculation.

$N(\%)$ or median [IQR] presented.

actions outside the documented record. The documentation may also have been influenced by the poor reimbursement for the coding of obesity. However, we believe that the documentation of obesity is necessary for ongoing clinical care and should be made regardless of the billing practices. We were not able to obtain data on the clustering of the encounters by provider. It is possible that providers who use the captured methods had more positive records than those who did not. However, the concept of "ever documentation" that credits even a single documentation and analysis at the patient-level overcomes this limitation. Observational study design carries the potential for uncontrolled confounding. However, the large sample size of this specialized age group may overcome this limitation.

\section{Conclusion}

For the first time, this research identifies poor rates of clinically documenting obesity in young children with severe obesity (including those under the age of 2 years) at two large academic children's hospitals utilizing a new, validated
EHR algorithm that uses structured and unstructured data to identify appropriate chart documentation. Given the importance of targeting this age group, these results show the need for improvement across all specialties in documentation of severe early onset obesity. With the increasing implementation of health information systems across the country, this offers a useful potential tool to enhance documentation in future, to avoid lifetime complications of excess weight and metabolic complications in the youngest children.

\section{Abbreviations \\ eMERGE: Electronic Medical Records and Genomics Project.}

\section{Additional Points}

What is Known on This Subject. Documentation of obesity in children and adults remains low despite availability of automated body mass index (BMI) calculation in 
TABLE 4: Ever documented versus never documented proportions and descriptions by demographic strata.

\begin{tabular}{|c|c|c|c|c|c|c|}
\hline & \multicolumn{2}{|c|}{ Overall } & \multicolumn{2}{|c|}{$\mathrm{BCH}$} & \multicolumn{2}{|c|}{ CCHMC } \\
\hline & $\begin{array}{c}\text { Ever } \\
\text { documented }\end{array}$ & $\begin{array}{c}\text { Never } \\
\text { documented }\end{array}$ & $\begin{array}{c}\text { Ever } \\
\text { documented }\end{array}$ & $\begin{array}{c}\text { Never } \\
\text { documented }\end{array}$ & $\begin{array}{c}\text { Ever } \\
\text { documented }\end{array}$ & $\begin{array}{c}\text { Never } \\
\text { documented }\end{array}$ \\
\hline$N$ unique patients & $557(21.5 \%)$ & $2031(78.5 \%)$ & $362(17 \%)$ & $1737(83 \%)$ & $195(40 \%)$ & $294(60 \%)$ \\
\hline Where first visit age $<2$ years (\%) & $150(15 \%)$ & $882(85 \%)$ & $109(12 \%)$ & $783(88 \%)$ & $41(29 \%)$ & $99(71 \%)$ \\
\hline Where first visit age $\geq 2$ years (\%) & $407(26 \%)$ & $1149(74 \%)$ & $253(21 \%)$ & $954(79 \%)$ & $154(44 \%)$ & $195(56 \%)$ \\
\hline \multicolumn{7}{|l|}{ Sex } \\
\hline Male & $289(17 \%)$ & $1378(83 \%)$ & $188(14 \%)$ & $1179(86 \%)$ & $101(34 \%)$ & $199(66 \%)$ \\
\hline Female & $268(29 \%)$ & $653(71 \%)$ & $174(24 \%)$ & $558(76 \%)$ & $94(50 \%)$ & $95(50 \%)$ \\
\hline \multicolumn{7}{|l|}{ Race } \\
\hline White & $237(19 \%)$ & $1025(81 \%)$ & $120(13 \%)$ & $815(87 \%)$ & $117(36 \%)$ & $210(64 \%)$ \\
\hline Black & $115(27 \%)$ & $304(73 \%)$ & $75(22 \%)$ & $262(78 \%)$ & $40(49 \%)$ & $42(51 \%)$ \\
\hline Other & $157(25 \%)$ & $473(75 \%)$ & $120(22 \%)$ & $432(78 \%)$ & $37(47 \%)$ & $41(53 \%)$ \\
\hline Unknown & $48(17 \%)$ & $229(83 \%)$ & $47(17 \%)$ & $228(83 \%)$ & $1(50 \%)$ & $1(50 \%)$ \\
\hline \multicolumn{7}{|l|}{ Ethnicity } \\
\hline Hispanic/Latino & $85(23 \%)$ & $284(77 \%)$ & $61(18 \%)$ & $270(82 \%)$ & $24(63 \%)$ & $14(37 \%)$ \\
\hline Not Hispanic/Latino & $330(23 \%)$ & $1107(77 \%)$ & $160(16 \%)$ & $828(84 \%)$ & $170(38 \%)$ & $279(62 \%)$ \\
\hline Unknown & $142(18 \%)$ & $640(82 \%)$ & $141(18 \%)$ & $639(82 \%)$ & $1(50 \%)$ & $1(50 \%)$ \\
\hline \multicolumn{7}{|c|}{ Description of ever versus never documented patients } \\
\hline$N$ visits per person & $4[3,6]$ & $3[2,4]$ & $4[3,7]$ & $3[2,4]$ & $4[2,6]$ & $3[2,4]$ \\
\hline Age at first visit, months & $39[22,51]$ & $32[17,49]$ & $36[20,48]$ & $31[16,48]$ & $44[26,57]$ & $38[19,54]$ \\
\hline BMI \% of the 95 percentile at first visit & $122[114,138]$ & $119[114,129]$ & $120[114,132]$ & $120[114,130]$ & $131[119,143]$ & $118[112,127]$ \\
\hline
\end{tabular}

TABLE 5: Characteristics of documentation of obesity.

\begin{tabular}{|c|c|c|c|}
\hline & Overall & $\mathrm{BCH}$ & CCHMC \\
\hline$N$ unique patients & 557 & 362 & 195 \\
\hline$N$ visits & 1336 & 867 & 467 \\
\hline$N$ documented visits per person & $2[1,3]$ & $2[1,3]$ & $2[1,3]$ \\
\hline Percent of visits correctly documented per person & $50[25,75] \%$ & $50[25,75] \%$ & $50[33,80] \%$ \\
\hline Patients correctly documented at 1st $99 \%$ percentile visit & $244(44 \%)$ & $130(36 \%)$ & $114(58 \%)$ \\
\hline Where first visit age $<2$ years & $35 / 150(23 \%)$ & $15 / 109(14 \%)$ & $20 / 41(49 \%)$ \\
\hline Where first visit age $\geq 2$ years & $209 / 407(51 \%)$ & $115 / 253(45 \%)$ & $94 / 154(61 \%)$ \\
\hline Age at first documentation, months & $48[35,60]$ & $48[35,60]$ & $48[35,59]$ \\
\hline Lag to documentation, months & $1.5[0,13]$ & $5[0,18]$ & $0[0,4]$ \\
\hline BMI $\%$ of $95 \%$ percentile at first documentation & $125[116,140]$ & $121[114,133]$ & $133[121,147]$ \\
\hline \multicolumn{4}{|l|}{$\%$ visits correctly documented, by clinic ${ }^{\mathrm{a}}$} \\
\hline Primary care & $191 / 1272(15 \%)$ & $151 / 1146(13 \%)$ & $40 / 126(32 \%)$ \\
\hline Obesity/endocrine/nutrition & $665 / 952(70 \%)$ & $505 / 731(69 \%)$ & $160 / 221(72 \%)$ \\
\hline Other subspecialty & $430 / 5051(9 \%)$ & $195 / 3584(5 \%)$ & $235 / 1467(16 \%)$ \\
\hline
\end{tabular}

${ }^{\mathrm{a}}$ Total visits with clinic indicated are 5461 for BCH ( 851 documented) and 1814 for CCHMC (435 documented).

$N(\%)$ or median [IQR] presented.

electronic health records. Acknowledgment of obesity by providers at an early age is an important first step towards intervention.

What This Study Adds. This study demonstrates that children under the age of 6 years are missed in the documentation of obesity. Physicians were found to be more vigilant in documenting obesity in girls and children from minority groups, presenting a significant opportunity for improvement.

\section{Competing Interests}

The authors have no potential conflict of interests to disclose.

\section{Authors' Contributions}

Drs. Cassandra C. Brady and Vidhu V. Thaker participated in the conception and design of the study, validated the extracted data, drafted the initial manuscript, and approved the final manuscript as submitted. Mr. Todd 
Lingren participated in the design of the study, performed data extraction, reviewed and edited the manuscript, and approved the final manuscript as submitted. Dr. Jessica G. Woo performed the statistical analyses, reviewed and edited the manuscript, and approved the final manuscript as submitted. Dr. Stephanie S. Kennebeck and Bahram Namjou-Khales participated in the eMERGE study that identified the cohort and reviewed and approved the final manuscript as submitted. Ms. Ashton Roach participated in data extraction and reviewed and approved the final manuscript as submitted. Dr. Jonathan P. Bickel and Mr. Nandan Patibandla are members of the eMERGE consortium, helped in data extraction, and reviewed and approved the final manuscript as submitted. Dr. Guergana K. Savova participated in the design and validation of the electronic algorithm that led to the identification of the cohort. Drs. Imre Solti, Ingrid A. Holm, John B. Harley, and Isaac S. Kohane lead the eMERGE consortium, facilitated the design and execution of the study, and reviewed and approved the final manuscript as submitted. Dr. Nancy A. Crimmins participated in the conception and design of the study and revised and approved the final manuscript as submitted.

\section{Acknowledgments}

This study was conducted under the auspices of Electronic Medical Records and Genomics (eMERGE) network. The eMERGE Network is initiated and funded by NHGRI through U01HG006828 (Cincinnati Children's Hospital Medical Center/Boston Children's Hospital). The study is funded in part by the NIH-NIDDK Grant nos. T32DK007699 and K12DK094721 and Nutrition and Obesity Research Center at Harvard (P30-DK040561) to VVT as well as institutional funding from Boston Children's Hospital and Cincinnati Children's Hospital and Medical Center. This study was performed as a part of the Electronic Medical Record and Genomics Network (eMERGE), initiated and funded by NHGRI, U01HG006828 (Cincinnati Children's Hospital Medical Center/Boston Children's Hospital). Dr. Thaker is also supported by NIDDK Grant nos. T32DK007699 and K12DK094721 and Nutrition and Obesity Research Center at Harvard (P30-DK040561).

\section{References}

[1] C. L. Ogden, M. D. Carroll, B. K. Kit, and K. M. Flegal, "Prevalence of obesity and trends in body mass index among US children and adolescents, 1999-2010," The Journal of the American Medical Association, vol. 307, no. 5, pp. 483-490, 2012.

[2] C. L. Ogden, M. D. Carroll, B. K. Kit, and K. M. Flegal, "Prevalence of childhood and adult obesity in the United States, 2011-2012," The Journal of the American Medical Association, vol. 311, no. 8, pp. 806-814, 2014.

[3] J. A. Skelton, S. R. Cook, P. Auinger, J. D. Klein, and S. E. Barlow, "Prevalence and trends of severe obesity among US children and adolescents," Academic Pediatrics, vol. 9, no. 5, pp. 322-329, 2009.

[4] A. S. Kelly, S. E. Barlow, G. Rao et al., "Severe obesity in children and adolescents: identification, associated health risks, and treatment approaches: a scientific statement from the American
Heart Association," Circulation, vol. 128, no. 15, pp. 1689-1712, 2013.

[5] C. L. Ogden, M. D. Carroll, L. R. Curtin, M. M. Lamb, and K. M. Flegal, "Prevalence of high body mass index in US children and adolescents, 2007-2008," The Journal of the American Medical Association, vol. 303, no. 3, pp. 242-249, 2010.

[6] J. C. Lo, B. Maring, M. Chandra et al., "Prevalence of obesity and extreme obesity in children aged 3-5 years," Pediatric Obesity, vol. 9, no. 3, pp. 167-175, 2014.

[7] D. S. Freedman, Z. Mei, S. R. Srinivasan, G. S. Berenson, and W. H. Dietz, "Cardiovascular risk factors and excess adiposity among overweight children and adolescents: the Bogalusa Heart Study," The Journal of Pediatrics, vol. 150, no. 1, pp. 1217.e2, 2007.

[8] A. C. Skinner, E. M. Perrin, L. A. Moss, and J. A. Skelton, "Cardiometabolic risks and severity of obesity in children and young adults," The New England Journal of Medicine, vol. 373, no. 14, pp. 1307-1317, 2015.

[9] S. A. Cunningham, M. R. Kramer, and K. M. V. Narayan, "Incidence of childhood obesity in the United States," The New England Journal of Medicine, vol. 370, no. 5, pp. 403-411, 2014.

[10] P. Danielsson, J. Kowalski, Ö. Ekblom, and C. Marcus, "Response of severely obese children and adolescents to behavioral treatment," Archives of Pediatrics \& Adolescent Medicine, vol. 166, no. 12, pp. 1103-1108, 2012.

[11] C. Knop, V. Singer, Y. Uysal, A. Schaefer, B. Wolters, and T. Reinehr, "Extremely obese children respond better than extremely obese adolescents to lifestyle interventions," Pediatric Obesity, vol. 10, no. 1, pp. 7-14, 2015.

[12] S. E. Barlow, "Expert committee recommendations regarding the prevention, assessment, and treatment of child and adolescent overweight and obesity: summary report," Pediatrics, vol. 120, supplement 4, pp. S164-S192, 2007.

[13] S. H. O’Brien, R. Holubkov, and E. C. Reis, "Identification, evaluation, and management of obesity in an academic primary care center," Pediatrics, vol. 114, no. 2, pp. e154-e159, 2004.

[14] S. Kuhle, S. F. L. Kirk, A. Ohinmaa, and P. J. Veugelers, "Comparison of ICD code-based diagnosis of obesity with measured obesity in children and the implications for health care cost estimates," BMC Medical Research Methodology, vol. 11, article 173, 2011.

[15] J. G. Woo, M. H. Zeller, K. Wilson, and T. Inge, "Obesity identified by discharge ICD-9 codes underestimates the true prevalence of obesity in hospitalized children," Journal of Pediatrics, vol. 154, no. 3, pp. 327-331, 2009.

[16] A. I. Patel, K. A. Madsen, J. H. Maselli, M. D. Cabana, R. S. Stafford, and A. L. Hersh, "Underdiagnosis of pediatric obesity during outpatient preventive care visits," Academic Pediatrics, vol. 10, no. 6, pp. 405-409, 2010.

[17] J. Keehbauch, G. San Miguel, L. Drapiza, J. Pepe, R. Bogue, and A. Smith-Dixon, "Increased documentation and management of pediatric obesity following implementation of an EMR upgrade and education," Clinical Pediatrics, vol. 51, no. 1, pp. 3138, 2012.

[18] H. J. Baer, A. S. Karson, J. R. Soukup, D. H. Williams, and D. W. Bates, "Documentation and diagnosis of overweight and obesity in electronic health records of adult primary care patients," JAMA Internal Medicine, vol. 173, no. 17, pp. 1648-1652, 2013.

[19] H. J. Baer, I. Cho, R. A. Walmer, P. A. Bain, and D. W. Bates, "Using electronic health records to address overweight and obesity: a systematic review," American Journal of Preventive Medicine, vol. 45, no. 4, pp. 494-500, 2013. 
[20] K. G. Shojania, A. Jennings, A. Mayhew, C. R. Ramsay, M. P. Eccles, and J. Grimshaw, "The effects of on-screen, point of care computer reminders on processes and outcomes of care," Cochrane Database of Systematic Reviews, no. 3, Article ID CD001096, 2009.

[21] T. Lingren, V. Thaker, C. Brady et al., "Developing an algorithm to detect early childhood obesity in two tertiary pediatric medical centers," Applied Clinical Informatics, vol. 7, no. 3, pp. 693-706, 2016.

[22] S. M. Roy, J. G. Spivack, M. S. Faith et al., "Infant BMI or weightfor-length and obesity risk in early childhood," Pediatrics, vol. 137, no. 5, Article ID e20153492, 2016.

[23] K. M. Flegal, R. Wei, C. L. Ogden, D. S. Freedman, C. L. Johnson, and L. R. Curtin, "Characterizing extreme values of body mass index-for-age by using the 2000 Centers for Disease Control and Prevention growth charts," The American Journal of Clinical Nutrition, vol. 90, no. 5, pp. 1314-1320, 2009.

[24] G. Hripcsak and A. S. Rothschild, "Agreement, the F-measure, and reliability in information retrieval," Journal of the American Medical Informatics Association, vol. 12, no. 3, pp. 296-298, 2005.

[25] A. C. Skinner and J. A. Skelton, "Prevalence and trends in obesity and severe obesity among children in the United States, 1999-2012," JAMA Pediatrics, vol. 168, no. 6, pp. 561-566, 2014.

[26] L. Benson, H. J. Baer, and D. C. Kaelber, “Trends in the diagnosis of overweight and obesity in children and adolescents: 19992007," Pediatrics, vol. 123, no. 1, pp. e153-e158, 2009.

[27] A. Cruz-Lagunas, L. Jiménez-Alvarez, G. Ramírez et al., "Obesity and pro-inflammatory mediators are associated with acute kidney injury in patients with $\mathrm{A} / \mathrm{H} 1 \mathrm{~N} 1$ influenza and acute respiratory distress syndrome," Experimental and Molecular Pathology, vol. 97, no. 3, pp. 453-457, 2014.

[28] L. V. Karnatovskaia, A. S. Lee, S. P. Bender, D. Talmor, and E. Festic, "Obstructive sleep apnea, obesity, and the development of acute respiratory distress syndrome," Journal of Clinical Sleep Medicine, vol. 10, no. 6, pp. 657-662, 2014.

[29] A. De Jong, N. Molinari, Y. Pouzeratte et al., "Difficult intubation in obese patients: Incidence, risk factors, and complications in the operating theatre and in intensive care units," British Journal of Anaesthesia, vol. 114, no. 2, pp. 297-306, 2015.

[30] O. O. Nafiu, C. C. Burke, R. Gupta, R. Christensen, P. I. Reynolds, and S. Malviya, "Association of neck circumference with perioperative adverse respiratory events in children," Pediatrics, vol. 127, no. 5, pp. el198-e1205, 2011.

[31] O. O. Nafiu, P. I. Reynolds, O. A. Bamgbade, K. K. Tremper, K. Welch, and J. Z. Kasa-Vubu, "Childhood body mass index and perioperative complications," Paediatric Anaesthesia, vol. 17, no. 5, pp. 426-430, 2007. 


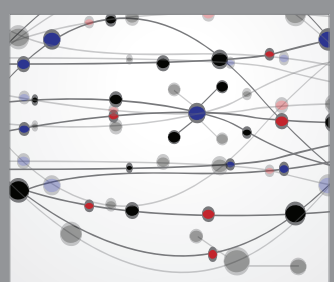

The Scientific World Journal
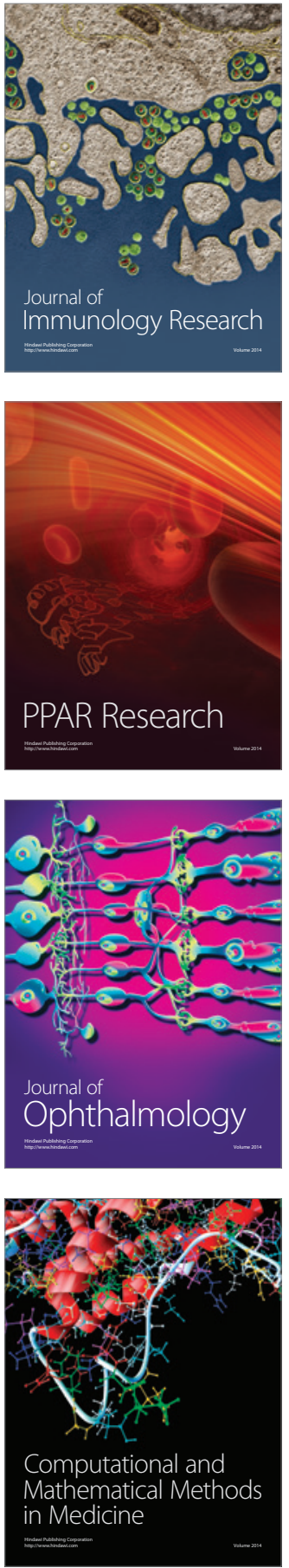

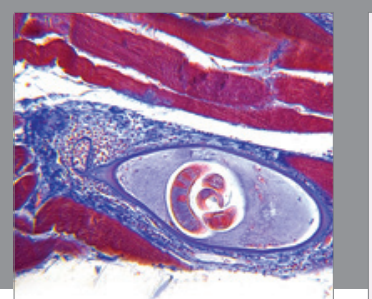

Gastroenterology Research and Practice

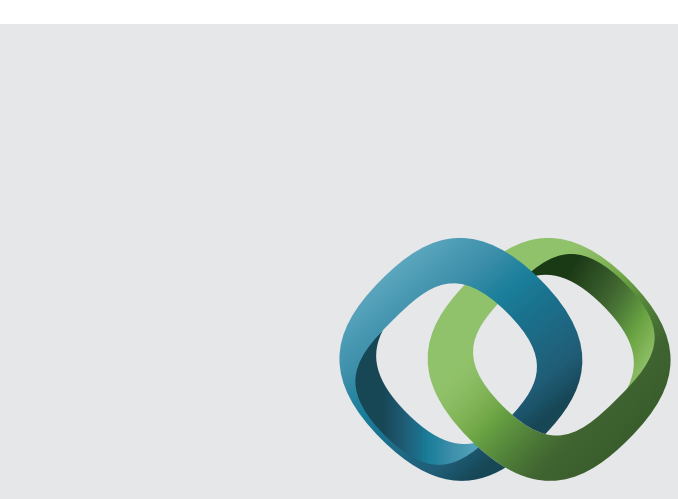

\section{Hindawi}

Submit your manuscripts at

http://www.hindawi.com
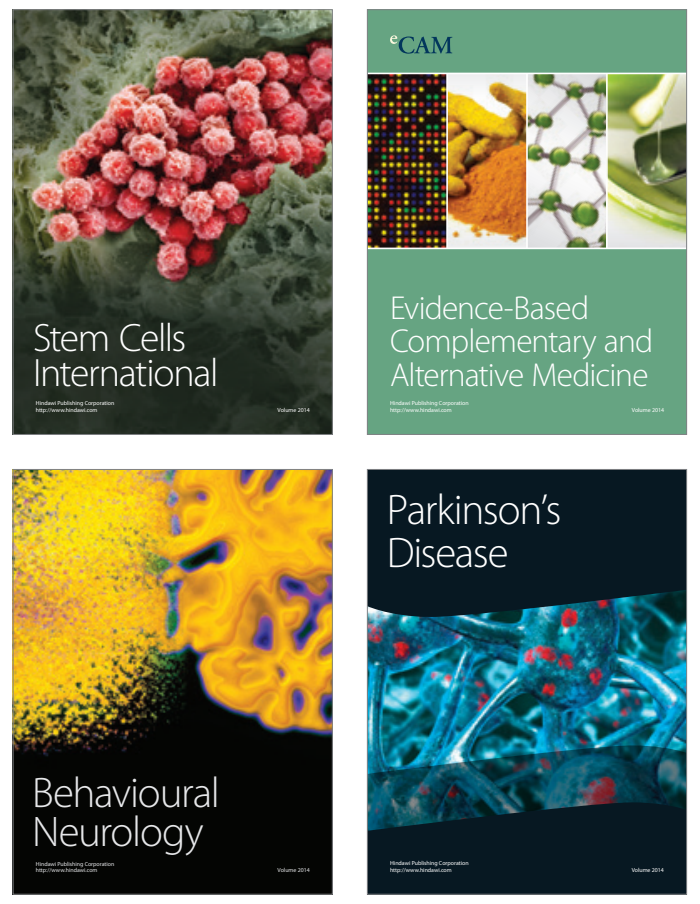
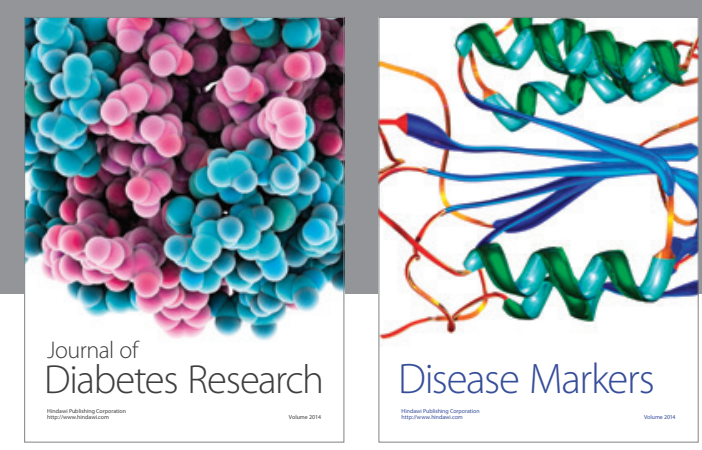

Disease Markers
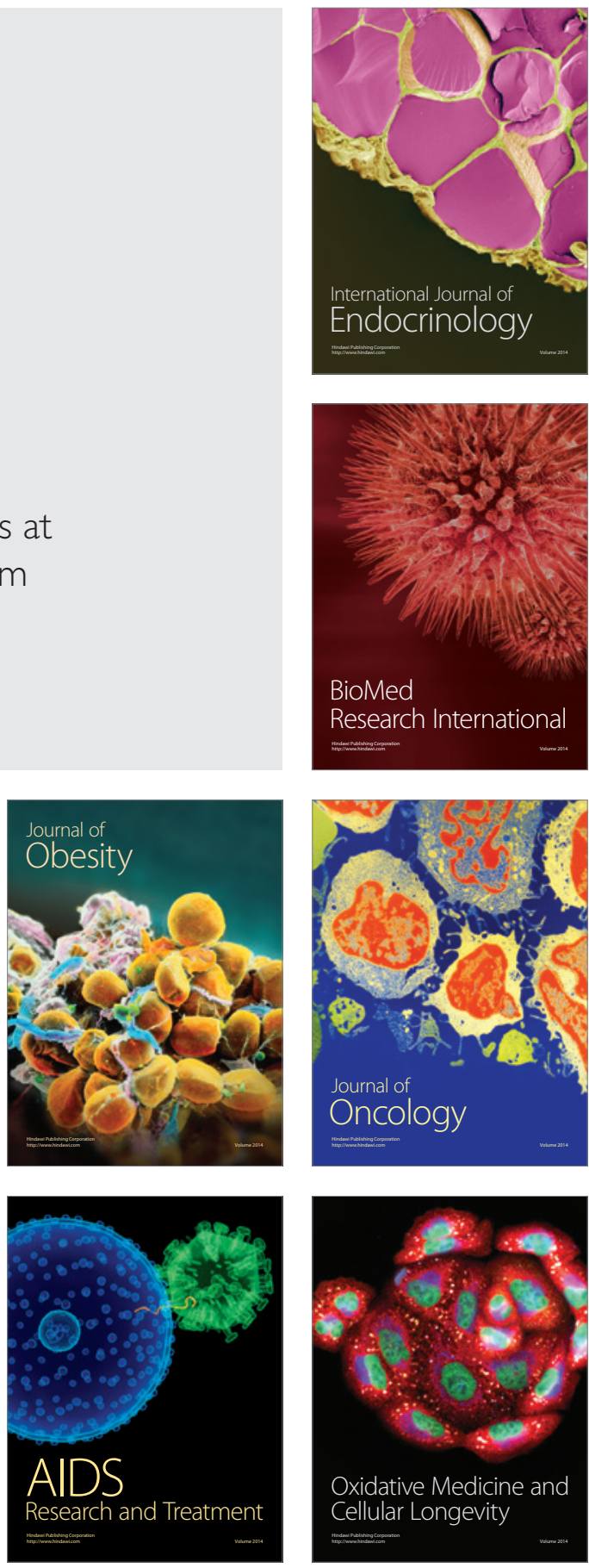